\title{
MIGRATION TO AND FROM STATE ECONOMIC AREAS IN THE INTERIOR SOUTHEAST: \\ AN EXPERIMENT USING POOLED CROSS-SECTION DATA: COMMENT
}

Robert Britt

West Virginia University

Richard Olsen's paper is an imaginative attempt to overcome severe data limitations in order to study gross migration flows to and from small economic areas. The literature on labor mobility suggests that the choice of small geographic areas and gross flows a re both worthwhile topics of further investigation. So we are really getting coverage of two relevant topics for one in this paper.

Cross-section data from the 1950 and 1960 Census of Population are pooled and a dummy or "pooled" variable is added with the value of "0" for 1950 and " 1 " for 1960. This pooling process does present some problems because of changes of definitions between census years. Annual migration rates are reported in the 1950 Census and five-year rates for 1960. Olsen is well aware that the choice of the method to transform the 1960 information into annual rates could significantly affect his results. Particular caution should be given, however, to the interpretation of the coefficient of the "pooled" variable. The negative relationship between this variable and migration flows is interpreted as implying a decline over time in the propensity to migrate. In reality, we should expect that dividing 1960 rates by 5 would consistently understate migration in this period in comparison with reported 1950 rates. The appendixindicates the "pooled"variable is sensitive to the annualization procedure.

Some interesting comparisons may be made between the results of this study and two other widely cited studies of gross migration by Ira Low ry and Lansing and Mueller. ${ }^{1}$ Lowry and Lansing and Mueller largely agree that two "characteristics of place" -- unemployment rates and income levels -are more important in determining the direction of inmigration than in generating a higher flow of outmigration. In the present study the reverse is true. The difference between local and national male unemployment rates is more important in determining outmigration than inmigration. Income or earnings is not included as an independent variable by Olsen.

According to Olsen's results, higher unemployment rates do appear deter inmigration, but the results are not statistically significant for all age groups. The results are less reliable for 25 to 34 year olds -- in other words individuals in the primary working ages who also generally exhibit high mobility. I suspect that the overall male unemployment rates used in the paper may not be indicative of job opportunities (or the lack of them) for individuals between 25 and 34 . In fact, if the re is considerable slack in the labor market, employer hiring practices frequently stipulate this age bracket simply as a screening device. What is more striking is the consistent relationship between unemployment rates and outmigration. Lowry and Lansing and Mueller dwelt at some length on the point that high unemployment does not appear to accelerate outmigration. Their results, however, were limited to metropolitan or larger labor market areas while the present study examines a cross section of rural and urban areas. I suspect there is greater variability in outmigration with respect to unemployment rates as we move from rural to more and more highly urbanized areas. This speculation could to tested with data used in the present study by plotting the residuals against 
population density for outmigration. ${ }^{2}$ Plots of two areas for different age groups are provided in the paper. While not conclusive, these plots do show the residuals are greater for the Knoxville area than for a non-metropolitan area in East Tennessee.

An index of male skills is also used by Olsen. Literally, this index is average national real income of employed males standardized by the occupational structure of each of the state economic areas. Indexes of this type are difficult to interpret, but in this case we get some useful results. The index is consistently significant and positively related to both in and outmig ration. Lansing and Mueller speculated that a reason why low income areas frequently have low rates of outmigration is that the income measure is partly an occupational index. The index developed here is avowedly an occupational index and apparently is successful in separating occupational from income effects enough to provide some useful results.

A major point of this exercise has been to develop techniques useful for regional forecasting. It is a little difficult to judge its success at this stage, but I fell it still provides some interesting informationabout the migration process. 
FOOTNOTES

$1_{\text {John B. Lansing and Eva Mueller, The Geographic Mobility of Labor }}$ (Ann Arbor: Institute for Social Research, 1967), Chapter 4; Ira S. Lowry, Migration and Metropolitan Growth: Two Analytical Models (San Francisco: Chandler Publishing Co., 1966).

${ }^{2}$ Plots of residuals were subsequently examined by Olsen. The se plots did not reveal any strong and systematic relationship between outmigration residuals and population density. Olsen has observed that the results of his study may well be influenced by the areas (interior Southeast) includedin the sample. 